\title{
Boxing Performance May Benefit from Pertaining of the Boxer to a Given Zodiacal Sign
}

\author{
André Mukala Nsengu Tshibangu \\ Department of Basic Sciences, Faculty of Pharmaceutical Sciences, University of Kinshasa, P.O. Box 212, \\ Kinshasa 11, Democratic Republic of the Congo \\ Email: andre28080@lycos.com
}

Received November $25^{\text {th }}$, 2013; revised December $25^{\text {th }}$, 2013; accepted January $5^{\text {th }}, 2014$

Copyright @ 2014 André Mukala Nsengu Tshibangu. This is an open access article distributed under the Creative Commons Attribution License, which permits unrestricted use, distribution, and reproduction in any medium, provided the original work is properly cited. In accordance of the Creative Commons Attribution License all Copyrights (C) 2014 are reserved for SCIRP and the owner of the intellectual property André Mukala Nsengu Tshibangu. All Copyright (C) 2014 are guarded by law and by SCIRP as a guardian.

The aim of the present study is not to provide the reader with a proof of astrology's validity. The present study has been undertaken in the aim of providing the coach with an original tool for identification of the candidates more advantaged than others to boxing practice, in the case that the coach has too numerous candidates to deal with. Microsoft Office Excel 2007 program has been used in the analysis of data gathered from BoxRec.com, the web based database, about the World top 100 male boxers BoxRec.com-rated, retired on March $26^{\text {th }}$, 2013. The study has shown that boxing performance may be influenced by pertaining of the boxer to given zodiacal signs: 1) Regarding all victories pulled together, the most disadvantaged are Sagittarius signs. As other zodiacal signs related to the element Fire, they probably rarely display tactful behavior. Their resulting impulsiveness may make them neglectful of their defense. 2) Regarding all losses pulled together, the most disadvantaged are Aquarius signs. As other zodiacal signs related to the element Air, they probably think too much before they act; and they tend to rise above conflict and to float around it. All that may affect negatively their attack velocity and defense velocity. 3) Regarding non-KO victories and $\mathrm{KO}$ losses, the most advantaged are Scorpio signs. Contrary to other Water signs which are used to detest all form of conflict, they often seek out challenges and problems, subliminally realizing that such challenges call forth their greatest strength and resources. That may probably help them not to neglect their attack, what is expectable in other Water signs. 4) Regarding all victories pulled together, all losses pulled together, and non-KO losses, the most advantaged are Virgo signs. Regarding $\mathrm{KO}$ victories, the most advantaged are Taurus signs. As other Earth signs, when driven back against a wall, Virgo and Taurus signs are capable of hitting the obstacle hard with full force. That is particularly true of Taurus, the fixed Earth, who will never seek out conflicts but who is capable of surprising power. The known soundness of Earth signs may help Virgo and Taurus signs to control both their attack and defense actions, performing them only when they feel that they are going to be successful. 5) Regarding boxers life spans, the most advantaged are Libra and Sagittarius signs.

Keywords: Astrology; Boxing; Elements; Performance; Zodiacal Signs

\section{Introduction}

\section{Sport Science and Sport Talent}

Athletes reach their full potential if some factors are combined: physical capacities, biomechanics, physiological capacities, psychological makeup, a work ethic that includes an appropriated attitude toward training, and the opportunity to compete with athletes of a similar or superior level, particularly during the process of sport talent development (Ackland, Bloomfield, \& Elliot, 2009).

If sport talent is to be fully developed, coaching based on sound sport science principles is an essential ingredient while "raw athletic talent" is the most important factor in the attainment of high levels of sporting performance (Ackland, Bloomfield, \& Elliot, 2009).

But, as far as we know, raw variables such as zodiacal sign, the element to which the zodiacal sign is related, or any other variable related to the athlete date of the birth, have not yet been used in the identification of sporting talent. However, obtaining such variables is relatively easy, taking into account the fact that their determination does not require so sophisticated tools as those required for the determination of most of other variables (equipment required for complete anthropometric assessment of athletes, video linked to appropriate software and a computer, etc).

\section{Astrology}

Speaking of an a-causal connecting principle that he calls law of correspondences "synchronicity", C.G. Jung, in reference to astrology, points out that whatever is born or done at a particular moment in time inevitably bears the qualities of that moment (Arroyo, 1975).

In the field of psychology, every theory of personality assumes that there is such a thing as "human nature" which the 
new-born brings with him into this world, chiefly in the form of general predispositions and potentialities rather than specific traits (Arroyo, 1975).

In the field of medicine, Dr. Eugen Jonas, a Czechoslovakian psychiatrist and gynecologist, found that a child conceived when there is an opposition of the sun and any larger planet (i.e., when the sun and the planet were $180^{\circ}$ in longitude from each other) has a much greater chance of suffering birth defects, miscarriage, mental retardation, and other factors which negatively affect his health (Arroyo, 1975). It is not unsound to expect that such a child be disadvantaged in the practice of boxing.

\section{Elements}

Reading Arroyo's book Astrology, psychology and the four elements: An energy approach to astrology \& its use in the counseling arts (1975) may help one learn what follows about the elements: 1) Every individual is composed of all four elements (Fire, Air, Water, and Earth) and cannot exist if even one of the elements is missing, for he would be totally devoid of the function of the related energy both psychologically and physically; 2) After the Medieval-Renaissance theory of the four humors (choler or yellow bile, blood, phlegm, and black bile) which was related to the elements of astrology, when these four humors were mixed in exactly the right proportions in an individual, he would be healthy and have a well-balanced personality, while a slight predominance of one humor or element (which we all have, according to our natal charts) affects not only a man's physical characteristics but also his complexion and temperament; 3) The elements most emphasized in a natal chart by planetary placement and the element of the Ascendant show what energies one is capable of utilizing rather easily in his or her everyday life, as well as in what realms of experience one can participate naturally and spontaneously; and 4) Elements that are lacking emphasis in the chart reveal an attunement which must be consciously cultivated and developed in order to afford the individual the minimal participation in that field of experience required for a full and well-rounded life.

It is not hence unsound to expect that boxing practice may be influenced by the predominance of any element (which we all have, according to our natal charts).

\section{Zodiacal Signs}

The zodiacal signs are the twelve primary patterns of energy resulting from the combination of the four elements and the three vibrational modalities: 1) cardinal (Aries, Libra, Cancer, and Capricorn); 2) fixed (Leo, Aquarius, Scorpio, and Taurus); and 3) mutable (Sagittarius, Gemini, Virgo, and Pisces).

The four elements are related to the zodiacal signs as follows: 1) Fire (Aries, Leo, and Sagittarius); 2) Air (Libra, Aquarius, and Gemini); 3) Water (Cancer, Scorpio, and Pisces); and 4) Earth (Capricorn, Taurus, and Virgo).

Thus, the element 'Earth' in the 'fixed' vibrational modality results in the zodiacal sign of Taurus, for instance.

\section{Astrology as a Tool for Identification of Boxing Talent}

As astrology enables a person to determine the type of activity in which his or her life-energies can flow with the greatest ease and satisfaction (Arroyo, 1975), used properly, it can help an individual to develop a greater degree of self-reliance and self-confidence: so often, a person feels deeply that he has special abilities in a certain area, for example, but the lack of confidence or trust in self may make it difficult to act upon this feeling (Arroyo, 1975).

From a standpoint of interest for the boxing coach we are, we expect astrology be used as a tool for identification of the candidates more advantaged than others to boxing practice, in the case that we have too numerous candidatures to deal with.

That has strengthened our desire to point out whether or not boxing performance is influenced by the 12 zodiacal signs (Aries, Leo, Sagittarius, Libra, Aquarius, Gemini, Cancer, Scorpio, Pisces, Capricorn, Taurus and Virgo) and/or by the 4 elements to which the 12 zodiacal signs are related.

Thus, the aim of the present article is not to provide the reader with a proof of astrology's validity: the article is aimed to provide the coach with a parameter that relate to success in boxing practice.

\section{Material and Methods}

The subjects enrolled in the present study are the World top 100 male professional boxers, BoxRec.com ranked, and retired in the period of time lasting from the beginning of professional boxing practice to March $26^{\text {th }}, 2013$.

Microsoft Office Excel 2007 program has been used in the analysis of data gathered from BoxRec.com, the web based database, about the boxers.

BoxRec.com failed to show the day of birth of one of the 100 boxers. We have thus dealt with the 99 remaining. The 99 boxers have been split into their respective zodiacal signs. The boxers falling into the different zodiacal signs have been grouped according to each of the 4 elements related to the signs: that resulted in 4 groups, each composed of boxers pertaining to 3 different zodiacal signs.

The number of all victories pulled together and all losses pulled together, the number knock-out (KO) victories and $\mathrm{KO}$ losses, as well as the number of draws made it possible to compute 1) non-KO victories and non-KO losses as well as 2) all matches fought pulled together for each boxer.

For each boxer, as a function of all matches pulled together, percentages have been computed: percentages of 1) all victories pulled together, 2) KO victories, 3) non-KO victories, 4) all losses pulled together, 5) KO losses, 6) non-KO losses, and 7) draws.

For each boxer, career length has been computed subtracting the debut year from the retirement year.

Regarding the boxers concerned by the present study but dead on March 26th, 2013, life span has been computed subtracting the boxer's year of birth from his year of death.

As a function of each zodiacal sign and as a function of each element, for each variable taken into account, it has been noted the number of the boxers concerned and it has been computed 1) a mean, and 2) the variance about the mean.

For each variable taken into account, the differences between the means have been examined for significance, considering both boxers number and the variance about the mean.

The number of values in each sample being less than 30 , and the data being presented not in the form of measurements but taking the form of percentages, we felt uneasy to assume that the population variances were equal (Parker, 1979). Testing the significance of the difference between two means by the Stu- 
dent's t test, we have thus used the following expressions in our computations.

$$
\begin{gathered}
t=\ddot{X}_{1}-\ddot{X}_{2} /\left[\left(s_{1}^{2} / N_{1}+s_{2}^{2} / N_{2}\right)\right]^{1 / 2} \\
1 / f=u^{2} /\left(N_{1}-1\right)+(1-u)^{2} /\left(N_{2}-1\right) \\
u=\left(s_{1}^{2} / N_{1}\right) /\left[\left(s_{1}^{2} / N_{1}\right)+\left(s_{2}^{2} / N_{2}\right)\right]
\end{gathered}
$$

In those expressions, $t$ is the Student's $t ; \ddot{X}$ is the mean of a sample; $s^{2}$ is the variance about the mean of the sample; $N$ is the number of values in the sample; $f$ expresses the degrees of freedom; and $u$ is defined by the above mentioned expression.

Probability significance level has been set at $\mathrm{p}=.05$ or less.

\section{Results}

\section{All Victories Pulled Together}

Regarding all victories pulled together (Table 1), it appears that 1) Virgo signs are significantly advantaged over 8 signs: Aries ( $\mathrm{p}<.05)$, Sagittarius ( $<.002)$, Aquarius ( $<.01)$, Libra $(\mathrm{p}<.01)$, Pisces $(\mathrm{p}<.01)$, Cancer $(\mathrm{p}<.05)$, Scorpio $(\mathrm{p}<.05)$ and Capricorn ( $\mathrm{p}<.05)$; 2$)$ Cancer signs $(\mathrm{p}<.05)$ as well as Capricorn signs $(p<.05)$ are significantly advantaged over Sagittarius signs; 3$)$ Cancer signs $(p<.05)$ are significantly advantaged over Libra signs and 4) other examinations showed no significant advantage of a sign over any other.

No significant difference has been found between the means of the 4 elements when comparison was called for (Table 2).

Table 1.

Zodiacal signs and all victories pulled together.

\begin{tabular}{cccc}
\hline Zodiacal sign & $\ddot{\boldsymbol{X}}$ & $\boldsymbol{N}$ & $\boldsymbol{s}^{2}$ \\
\hline Aries & 83.91318734 & 12 & 83.8066278 \\
Leo & 81.60009743 & 6 & 97.5130136 \\
Sagittarius & 76.03149533 & 8 & 73.89508743 \\
Aquarius & 79.16251863 & 8 & 31.85124549 \\
Gemini & 83.66430069 & 9 & 95.00474424 \\
Libra & 78.30557205 & 9 & 51.39683343 \\
Pisces & 73.19526559 & 6 & 126.0123499 \\
Cancer & 84.99041357 & 12 & 44.51835664 \\
Scorpio & 82.94824515 & 5 & 37.60085205 \\
Capricorn & 84.64545933 & 9 & 50.33843022 \\
Taurus & 84.77353878 & 10 & 99.17500424 \\
Virgo & 92.4350745 & 5 & 31.96920193 \\
\hline
\end{tabular}

$\ddot{X}$ is the mean of a sample; $N$ is the number of values in the sample; $s^{2}$ is the variance about the mean of the sample.

Table 2.

Elements and all victories pulled together.

\begin{tabular}{cccc}
\hline Element & $\ddot{\boldsymbol{X}}$ & $\boldsymbol{N}$ & $\boldsymbol{s}^{2}$ \\
\hline Fire & 80.5149267 & 3 & 16.41346387 \\
Air & 80.37746379 & 3 & 8.286061958 \\
Water & 80.37797477 & 3 & 39.73609629 \\
Earth & 87.28469087 & 3 & 19.8989397 \\
\hline
\end{tabular}

$\ddot{X}$ is the mean of a sample; $N$ is the number of values in the sample; $s^{2}$ is the variance about the mean of the sample.

\section{KO Victories}

Regarding KO victories (Table 3), it appears that 1) Taurus signs are significantly advantaged over 3 signs: Sagittarius ( $\mathrm{p}$ $<.05)$, Aquarius $(\mathrm{p}<.05)$ and Scorpio $(\mathrm{p}<.05)$; and 2$)$ other examinations showed no significant advantage of a sign over any other.

No significant difference has been found between the means of the 4 elements when comparison was called for (Table 4).

\section{Non-KO Victories}

Regarding non-KO victories (Table 5), it appears that 1 ) Scorpio signs are significantly advantaged over 2 signs: Cancer $(\mathrm{p}<.05)$ and Taurus $(\mathrm{p}<.02) ; 2)$ Sagittarius signs are significantly advantaged over 1 sign: Taurus ( $<.05)$; and 3 ) other examinations showed no significant advantage of a sign over any other.

No significant difference has been found between the means of the 4 elements when comparison was called for (Table 6).

\section{All Losses Pulled Together}

Regarding all losses pulled together (Table 7), it appears that 1) Virgo signs are significantly advantaged over 3 signs: Sagittarius ( $\mathrm{p}<.01)$, Aquarius $(\mathrm{p}<.01)$ and Libra $(\mathrm{p}<.01) ; 2)$ Aries signs $(\mathrm{p}<.05)$, Cancer signs $(\mathrm{p}<.05)$, Scorpio signs $(\mathrm{p}<.05)$ and Capricorn signs $(\mathrm{p}<.05)$ are each of them significantly

Table 3.

Zodiacal signs and KO victories.

\begin{tabular}{cccc}
\hline Zodiacal sign & $\ddot{\boldsymbol{X}}$ & $\boldsymbol{N}$ & $\boldsymbol{s}^{2}$ \\
\hline Aries & 46.84293353 & 12 & 486.5956572 \\
Leo & 44.4479851 & 6 & 313.1653282 \\
Sagittarius & 33.14471636 & 8 & 338.3689657 \\
Aquarius & 37.37080691 & 8 & 238.4347602 \\
Gemini & 46.49254903 & 9 & 365.0702419 \\
Libra & 37.40654348 & 9 & 431.2477423 \\
Pisces & 38.34717284 & 6 & 381.2088096 \\
Cancer & 49.2523434 & 12 & 234.468005 \\
Scorpio & 30.19826532 & 5 & 348.1327246 \\
Capricorn & 42.288821 & 9 & 399.4293451 \\
Taurus & 54.80314877 & 10 & 248.5211085 \\
Virgo & 56.49559635 & 5 & 576.568537 \\
\hline
\end{tabular}

$\ddot{X}$ is the mean of a sample; $N$ is the number of values in the sample; $s^{2}$ is the variance about the mean of the sample.

Table 4.

Elements and $\mathrm{KO}$ victories.

\begin{tabular}{cccc}
\hline Element & $\ddot{X}$ & $N$ & $\boldsymbol{s}^{2}$ \\
\hline Fire & 41.478545 & 3 & 53.5234693 \\
Air & 40.42329981 & 3 & 27.62715891 \\
Water & 39.26592719 & 3 & 91.39755505 \\
Earth & 51.19585538 & 3 & 60.21754066 \\
\hline
\end{tabular}

$\ddot{X}$ is the mean of a sample; $N$ is the number of values in the sample; $s^{2}$ is the variance about the mean of the sample. 


\section{A. M. N. TSHIBANGU}

Table 5.

Zodiacal signs and non-KO victories.

\begin{tabular}{cccc}
\hline Zodiacal sign & $\ddot{\boldsymbol{X}}$ & $\boldsymbol{N}$ & $\boldsymbol{s}^{2}$ \\
\hline Aries & 37.07025381 & 12 & 319.7290171 \\
Leo & 37.15211233 & 6 & 118.6470845 \\
Sagittarius & 42.88677897 & 8 & 146.7620997 \\
Aquarius & 41.79171172 & 8 & 175.9270857 \\
Gemini & 37.17175165 & 9 & 178.2631472 \\
Libra & 40.89902857 & 9 & 282.4080593 \\
Pisces & 34.84809276 & 6 & 151.3189416 \\
Cancer & 35.73807017 & 12 & 116.0983419 \\
Scorpio & 52.74997983 & 5 & 180.0105193 \\
Capricorn & 42.35663833 & 9 & 306.7192033 \\
Taurus & 29.97039001 & 10 & 116.7584076 \\
Virgo & 35.93947815 & 5 & 479.1889427 \\
\hline
\end{tabular}

$\ddot{X}$ is the mean of a sample; $N$ is the number of values in the sample; $s^{2}$ is the variance about the mean of the sample.

Table 6.

Elements and non-KO victories.

\begin{tabular}{cccc}
\hline Element & $\ddot{\mathbf{X}}$ & $\boldsymbol{N}$ & $\boldsymbol{s}^{2}$ \\
\hline Fire & 39.0363817 & 3 & 11.12084454 \\
Air & 39.95416398 & 3 & 6.005584574 \\
Water & 41.11204759 & 3 & 101.7791152 \\
Earth & 36.0888355 & 3 & 38.37151758 \\
\hline
\end{tabular}

$\ddot{X}$ is the mean of a sample; $N$ is the number of values in the sample; $s^{2}$ is the variance about the mean of the sample.

Table 7.

Zodiacal signs and all losses pulled together.

\begin{tabular}{cccc}
\hline Zodiacal sign & $\ddot{\boldsymbol{X}}$ & $\boldsymbol{N}$ & $\boldsymbol{s}^{2}$ \\
\hline Aries & 11.29042244 & 12 & 54.67385975 \\
Leo & 15.30725303 & 6 & 100.227858 \\
Sagittarius & 17.38010321 & 8 & 46.93096084 \\
Aquarius & 17.49755347 & 8 & 21.50414768 \\
Gemini & 11.35434061 & 9 & 48.64422998 \\
Libra & 16.19893442 & 9 & 20.58879611 \\
Pisces & 15.45423872 & 6 & 88.92567927 \\
Cancer & 12.13432083 & 12 & 36.34393642 \\
Scorpio & 11.4731742 & 5 & 11.53450347 \\
Capricorn & 11.35057511 & 9 & 38.48425728 \\
Taurus & 12.38874365 & 10 & 66.51521347 \\
Virgo & 6.325166291 & 5 & 24.35500007 \\
\hline
\end{tabular}

$\ddot{X}$ is the mean of a sample; $N$ is the number of values in the sample; $s^{2}$ is the variance about the mean of the sample.

advantaged over 1 sign: Aquarius; and 3) other examinations showed no significant advantage of a sign over any other.

No significant difference has been found between the means of the 4 elements when comparison was called for (Table 8).

\section{KO Losses}

Regarding KO losses (Table 9), it appears that 1) Scorpio signs are significantly advantaged over 4 signs: Aquarius (p $<.05)$, Pisces ( $<.05)$, Cancer $(\mathrm{p}<.05)$ and Taurus $(\mathrm{p}<.05)$; and 2 ) other examinations showed no significant advantage of a sign over any other.

No significant difference has been found between the means of the 4 elements when comparison was called for (Table 10).

\section{Non-KO Losses}

Regarding non-KO losses (Table 11), it appears that 1) Virgo signs are significantly advantaged over 3 signs: Sagittarius ( $\mathrm{p}<.02)$, Aquarius $(\mathrm{p}<.05)$ and Libra $(\mathrm{p}<.05)$; and 2$)$ other examinations showed no significant advantage of a sign over any other.

Table 8.

Elements and all losses pulled together.

\begin{tabular}{cccc}
\hline Element & $\ddot{X}$ & $N$ & $\boldsymbol{s}^{2}$ \\
\hline Fire & 14.65925956 & 3 & 9.585974616 \\
Air & 15.01694283 & 3 & 10.48259415 \\
Water & 13.02057792 & 3 & 4.551307393 \\
Earth & 10.02149502 & 3 & 10.51658303 \\
\hline
\end{tabular}

$\ddot{X}$ is the mean of a sample; $N$ is the number of values in the sample; $s^{2}$ is the variance about the mean of the sample.

Table 9.

Zodiacal signs and $\mathrm{KO}$ losses.

\begin{tabular}{cccc}
\hline Zodiacal sign & $\ddot{\boldsymbol{X}}$ & $\boldsymbol{N}$ & $\boldsymbol{s}^{2}$ \\
\hline Aries & 3.001703214 & 12 & 6.145236275 \\
Leo & 3.293868626 & 6 & 4.870855998 \\
Sagittarius & 2.437144414 & 8 & 1.246708591 \\
Aquarius & 3.957281385 & 8 & 5.762328159 \\
Gemini & 1.863145238 & 9 & 1.909107821 \\
Libra & 3.589898907 & 9 & 7.834428762 \\
Pisces & 3.689208654 & 6 & 3.786382572 \\
Cancer & 3.025605571 & 12 & 4.332431888 \\
Scorpio & 1.412244726 & 5 & .650928522 \\
Capricorn & 2.913095863 & 9 & 9.908470539 \\
Taurus & 3.68102577 & 10 & 7.534817256 \\
Virgo & 1.696871293 & 5 & 3.640733892 \\
\hline
\end{tabular}

$\ddot{X}$ is the mean of a sample; $N$ is the number of values in the sample; $s^{2}$ is the variance about the mean of the sample.

Table 10.

Elements and $\mathrm{KO}$ losses.

\begin{tabular}{cccc}
\hline Element & $\ddot{\boldsymbol{X}}$ & $\boldsymbol{N}$ & $\boldsymbol{s}^{2}$ \\
\hline Fire & 2.910905418 & 3 & .189677274 \\
Air & 3.136775177 & 3 & 1.250342387 \\
Water & 2.70901965 & 3 & 1.371311166 \\
Earth & 2.763664309 & 3 & 1.000964589 \\
\hline
\end{tabular}

$\ddot{X}$ is the mean of a sample; $N$ is the number of values in the sample; $s^{2}$ is the variance about the mean of the sample. 


\section{A. M. N. TSHIBANGU}

No significant difference has been found between the means of the 4 elements when comparison was called for (Table 12).

\section{Draws}

Regarding draws (Table 13), it appears that 1) Virgo signs showed significantly less draws than 4 signs: Aries $(\mathrm{p}<.02)$, Sagittarius ( $<$.02), Libra $(\mathrm{p}<.02)$ et Cancer $(\mathrm{p}<.05)$; and 2$)$ other examinations showed no significant advantage of a sign over any other.

No significant difference has been found between the means of the 4 elements when comparison was called for (Table 14).

\section{Career Length}

Regarding career length (Table 15), examinations revealed nothing but non-significant differences between the means of zodiacal signs.

No significant difference has been found between the means of the 4 elements when comparison was called for (Table 16).

\section{Life Span}

Regarding life span of the boxers concerned by the present study but dead on March 26th, 2013 (Table 17), it appears that 1) Libra signs had life spans significantly longer than those of 3 signs: Leo $(\mathrm{p}<.02)$, Capricorn ( $<$.05) and Taurus ( $<$.02); 2$)$ Sagittarius signs had a life span significantly longer than that of 1 sign: Leo ( $<.05)$; and 3) other examinations showed no significant advantage of a sign over any other.

No significant difference has been found between the means of the 4 elements when comparison was called for (Table 18).

Table 11.

Zodiacal signs and non-KO losses.

\begin{tabular}{cccc}
\hline Zodiacal sign & $\ddot{\boldsymbol{X}}$ & $\boldsymbol{N}$ & $\boldsymbol{s}^{\mathbf{2}}$ \\
\hline Aries & 8.288719228 & 12 & 57.6707252 \\
Leo & 12.0133844 & 6 & 108.1005093 \\
Sagittarius & 14.9429588 & 8 & 48.65849526 \\
Aquarius & 13.54027208 & 8 & 17.36519814 \\
Gemini & 9.491195369 & 9 & 41.66439525 \\
Libra & 12.60903551 & 9 & 29.3493229 \\
Pisces & 11.76503006 & 6 & 103.5700311 \\
Cancer & 9.108715263 & 12 & 28.24934391 \\
Scorpio & 10.06092947 & 5 & 13.91625899 \\
Capricorn & 8.437479248 & 9 & 54.18521268 \\
Taurus & 8.707717885 & 10 & 66.02220865 \\
Virgo & 4.628294998 & 5 & 31.46452108 \\
\hline
\end{tabular}

$\ddot{X}$ is the mean of a sample; $N$ is the number of values in the sample; $s^{2}$ is the variance about the mean of the sample.

Table 12.

Elements and non-KO losses.

\begin{tabular}{cccc}
\hline Element & $\ddot{\boldsymbol{X}}$ & $\boldsymbol{N}$ & $\boldsymbol{s}^{\mathbf{2}}$ \\
\hline Fire & 11.74835414 & 3 & 11.12240684 \\
Air & 11.88016765 & 3 & 4.497191827 \\
Water & 10.31155827 & 3 & 1.811113175 \\
Earth & 7.25783071 & 3 & 5.204100776 \\
\hline
\end{tabular}

$\ddot{X}$ is the mean of a sample; $N$ is the number of values in the sample; $s^{2}$ is the variance about the mean of the sample.
Table 13.

Zodiacal signs and draws.

\begin{tabular}{cccc}
\hline Zodiacal sign & $\ddot{\boldsymbol{X}}$ & $\boldsymbol{N}$ & $\boldsymbol{s}^{2}$ \\
\hline Aries & 4.79639022 & 12 & 17.51136478 \\
Leo & 3.092649548 & 6 & 11.14163748 \\
Sagittarius & 6.588401461 & 8 & 18.75747076 \\
Aquarius & 3.339927903 & 8 & 7.109209626 \\
Gemini & 4.981358704 & 9 & 31.51504344 \\
Libra & 5.495493529 & 9 & 14.67484805 \\
Pisces & 11.35049569 & 6 & 106.8584545 \\
Cancer & 2.875265599 & 12 & 3.894615946 \\
Scorpio & 5.578580654 & 5 & 12.0446888 \\
Capricorn & 4.003965554 & 9 & 12.29146562 \\
Taurus & 2.837717564 & 10 & 4.90196972 \\
Virgo & 1.239759213 & 5 & 1.001023988 \\
\hline
\end{tabular}

$\ddot{X}$ is the mean of a sample; $N$ is the number of values in the sample; $s^{2}$ is the variance about the mean of the sample.

Table 14.

Elements and draws.

\begin{tabular}{cccc}
\hline Element & $\ddot{\boldsymbol{X}}$ & $\boldsymbol{N}$ & $\boldsymbol{s}^{2}$ \\
\hline Fire & 4.825813743 & 3 & 3.055719667 \\
Air & 4.605593379 & 3 & 1.267515477 \\
Water & 6.601447314 & 3 & 18.74207342 \\
Earth & 2.69381411 & 3 & 1.925740326 \\
\hline
\end{tabular}

$\ddot{X}$ is the mean of a sample; $N$ is the number of values in the sample; $s^{2}$ is the variance about the mean of the sample.

Table 15.

Zodiacal signs and career length.

\begin{tabular}{cccc}
\hline Zodiacal sign & $\ddot{X}$ & $\boldsymbol{N}$ & $\boldsymbol{s}^{\mathbf{2}}$ \\
\hline Aries & 18.41666667 & 12 & 39.71969697 \\
Leo & 17.33333333 & 6 & 16.26666667 \\
Sagittarius & 18.375 & 8 & 25.41071429 \\
Aquarius & 15.75 & 8 & 14.78571429 \\
Gemini & 17.66666667 & 9 & 43 \\
Libra & 19 & 9 & 55.5 \\
Pisces & 16.5 & 6 & 17.1 \\
Cancer & 17 & 12 & 34.90909091 \\
Scorpio & 17.6 & 5 & 56.3 \\
Capricorn & 15.55555556 & 9 & 14.52777778 \\
Taurus & 17.8 & 10 & 40.62222222 \\
Virgo & 15.8 & 5 & 43.2 \\
\hline
\end{tabular}

$\ddot{X}$ is the mean of a sample; $N$ is the number of values in the sample; $s^{2}$ is the variance about the mean of the sample.

Table 16.

Elements and career length.

\begin{tabular}{cccc}
\hline Element & $\ddot{\boldsymbol{X}}$ & $\boldsymbol{N}$ & $\boldsymbol{s}^{\mathbf{2}}$ \\
\hline Fire & 18.04166667 & 3 & .376736111 \\
Air & 17.47222222 & 3 & 2.668981481 \\
Water & 17.03333333 & 3 & .303333333 \\
Earth & 16.38518519 & 3 & 1.516213992 \\
\hline
\end{tabular}

$\ddot{X}$ is the mean of a sample; $N$ is the number of values in the sample; $s^{2}$ is the variance about the mean of the sample. 


\section{A. M. N. TSHIBANGU}

Table 17.

Zodiacal signs and life span.

\begin{tabular}{cccc}
\hline Zodiacal sign & $\ddot{\boldsymbol{X}}$ & $\boldsymbol{N}$ & $\boldsymbol{s}^{\mathbf{2}}$ \\
\hline Aries & 68.4 & 10 & 145.3777778 \\
Leo & 54 & 5 & 188.5 \\
Sagittarius & 74.375 & 8 & 347.9821429 \\
Aquarius & 67 & 6 & 120.8 \\
Gemini & 64.85714286 & 7 & 339.8095238 \\
Libra & 79.71428571 & 7 & 120.5714286 \\
Pisces & 68.66666667 & 6 & 347.8666667 \\
Cancer & 71.16666667 & 6 & 92.16666667 \\
Scorpio & 69.25 & 4 & 172.25 \\
Capricorn & 68.42857143 & 7 & 55.95238095 \\
Taurus & 64.71428571 & 7 & 58.9047619 \\
Virgo & 68 & 3 & 417
\end{tabular}

$\ddot{X}$ is the mean of a sample; $N$ is the number of values in the sample; $s^{2}$ is the variance about the mean of the sample.

Table 18.

Elements and life span.

\begin{tabular}{cccc}
\hline Element & $\ddot{\boldsymbol{X}}$ & $\boldsymbol{N}$ & $\boldsymbol{s}^{\mathbf{2}}$ \\
\hline Fire & 65.59166667 & 3 & 109.7002083 \\
Air & 70.52380952 & 3 & 64.49659864 \\
Water & 69.69444444 & 3 & 1.710648148 \\
Earth & 67.04761905 & 3 & 4.129251701 \\
\hline
\end{tabular}

$\ddot{X}$ is the mean of a sample; $N$ is the number of values in the sample; $s^{2}$ is the variance about the mean of the sample.

\section{Discussion}

No significant difference has been found between the means of the 4 elements when comparison was called for, regarding any of the variables taken into account in the present study. However, the functions of energies related to the four elements may explain the few significant results found between the means of the 12 zodiacal signs when comparison was called for, regarding afore said variables taken into account.

In her book on chart comparisons How to Handle Your Human Relations, Lois H. Sargent gives great importance to the elements as a means of understanding how different people approach problem-solving (Arroyo, 1975). Psychologist Ralph Metzner studied the relationship that exists between the elements and personality types, as well as the astrological correlations with the elements (Arroyo, 1975). According to those studies, from the standpoint of dealing with conflicts or obstacles in their lives, there exist four types of people: Fire signs, Air signs, Water signs, and Earth signs.

Success in boxing competition requires from the boxer quantitatively to neglect neither attack nor defense actions; to perform those actions with sufficient velocity; and to manage soundly one's energy, attacking only when one feels that he is not going to fail the intended action.

\section{Fire Signs and Boxing Competition}

The impulsiveness of a boxer may make him neglectful of his defense. The legal targets of his body are thus easy to reach by his opponents. The boxer is hence more prone to be won than to be winner of his opponent.

In Sargent's opinion, the Fire signs respond to situations with intensity, desiring direct action in the solving of problems, and tending more to impulse than deliberation. According to Metzner, the Fire signs tend to overpower obstacles, to burn them up, or to scare them away through show of force, and they rarely display behavior that could be termed tactful.

It is not thus surprising that regarding all victories pulled together, it appears in the present study that the most disadvantaged are Sagittarius (Fire) signs: they show less victories than 3 signs: Cancer $(\mathrm{p}<.05)$, Capricorn $(\mathrm{p}<.05)$, and Virgo ( $<.002)$.

\section{Air Signs and Boxing Competition}

The attack velocity and defense velocity may be negatively affected in a boxer who is busy thinking too much for a pugilist as well as in a boxer who attacks with a too low frequency. The boxer is thus more loser-prone than winner-prone.

According to Sargent, the Air signs people like to reason things out and generally think before they act. In Metzner's mind, the Air signs tend to rise above conflict and to float around it.

Consequence of that may be reflected in the results we have obtained, according to which, regarding all losses pulled together, it appears that the most disadvantaged are Aquarius (Air) signs: they show more losses than 5 signs: Aries $(\mathrm{p}<.05)$, Cancer $(\mathrm{p}<.05)$, Scorpio $(\mathrm{p}<.05)$, Capricorn $(\mathrm{p}<.05)$, and Virgo $(\mathrm{p}<.01)$.

\section{Water Signs and Boxing Competition}

When a boxer has no control over his emotions, he may be so impressionable that he may be most of the time defending himself and neglecting his attack of which normally depend any victory his, either $\mathrm{KO}$ or non-KO.

In Sargent's mind, the Water signs are impressionable, sensitive, and intuitive. They incline to wait on circumstances for guidance in solving problems. In Metzner's opinion, the Water signs also detest all form of conflict (with the exception of some Scorpios). They tend to flow around it, over it, or - if all else fails - to slowly wear away the person or thing in their path. Scorpio, however, often seeks out challenges and problems, subliminally realizing that such challenges call forth their greatest strength and resources. Still, Scorpio most of the time will maintain a pregnant silence, not wanting to cause unnecessary conflict.

That may explain why, regarding non-KO victories, it appears after our results that the most advantaged are Scorpio (Water) signs: they show significantly more victories than 2 signs [Cancer $(\mathrm{p}<.05)$ and Taurus $(\mathrm{p}<.02)$ ], despite the fact that 2 Earth signs are the most advantaged, speaking of all victories pulled together and KO victories. The Scorpio (Water) signs also show significantly less $\mathrm{KO}$ losses than 4 signs: Aquarius $(\mathrm{p}<.05)$, Pisces $(\mathrm{p}<.05)$, Cancer $(\mathrm{p}<.05)$ and Taurus $(\mathrm{p}<.05)$.

\section{Earth Signs and Boxing Competition}

A boxer may be so sound that he controls both his attack and defense actions, performing them only when he feels that he is 
going to be successful.

In Sargent's opinion, the Earth signs are motivated by the desire for practical, useful results. They usually have sound common sense, whether they use it or not. According to Metzner, the Earth signs tend to disdain conflict. However, if they are driven back against a wall, they are capable of hitting the obstacle hard with full force. This is particularly true of Taurus, the fixed Earth, who will never seek out conflicts but who is capable of surprising power and anger if pushed too far.

That is consistent with our results according to which: 1) Regarding all victories pulled together, it appears that the most advantaged are Virgo (Earth) signs: they show significantly more victories than 8 signs [Aries $(\mathrm{p}<.05)$, Sagittarius ( $\mathrm{p}$ $<.002)$, Aquarius $(\mathrm{p}<.01)$, Libra $(\mathrm{p}<.01)$, Pisces $(\mathrm{p}<.01)$, Cancer ( $<. .05)$, Scorpio $(\mathrm{p}<.05)$, and Capricorn $(\mathrm{p}<.05)$ ]; 2 ) Regarding KO victories, it appears that the most advantaged are Taurus (Earth) signs: they show the afore mentioned surprising power, being significantly advantaged over 3 signs [Sagittarius $(\mathrm{p}<.05)$, Aquarius $(\mathrm{p}<.05)$ and Scorpio $(\mathrm{p}<.05)$ ]; 3$)$ Regarding all losses pulled together, it appears that the most advantaged are Virgo (Earth) signs: they show significantly less losses than 3 signs [Sagittarius $(\mathrm{p}<.01)$, Aquarius $(\mathrm{p}<.01)$ and Libra ( $<$.01)]; 4) Regarding non-KO losses, it appears that the most advantaged Virgo (Earth) signs show significantly less losses than 3 signs [Sagittarius $(p<.02)$, Aquarius $(p<.05)$ and Libra $(\mathrm{p}<.05)]$.

\section{Signs and Boxing Career Length}

Regarding career length, significant difference has been found when comparison was called neither between the means of the 4 elements nor between the means of the 12 zodiacal signs. The functions of energies related to the four elements do not help us explain the reason why.

\section{Signs and Boxers Life Spans}

Regarding life spans, the functions of energies related to the four elements also do not help us explain 1) the absence of significant difference between the means of the 4 elements; 2) the significantly longer life spans of Libra signs over 3 signs [Leo $(\mathrm{p}<.02)$, Capricorn $(\mathrm{p}<.05)$ and Taurus $(\mathrm{p}<.02)$ ]; and the significantly longer life spans of Sagittarius signs over 1 sign $[$ Leo $(\mathrm{p}<.05)]$.

\section{Conclusions}

At the end of the present study dealt with in the top 100 male boxers BoxRec.com-rated, retired on March 26 $6^{\text {th }}$, 2013, we draw the following conclusions:

1) No significant difference exists between the means of the 4 elements when comparison is called for, regarding any of the variables taken into account in the present study.

2) Regarding all victories pulled together, the most disad- vantaged are Sagittarius signs. As other zodiacal signs related to the element Fire, they probably rarely display tactful behavior. Their resulting impulsiveness may have made them neglectful of their defense.

3) Regarding all losses pulled together, the most disadvantaged are Aquarius signs. As other zodiacal signs related to the element Air, they probably think too much before they act; and they tend to rise above conflict and to float around it. All that may have affected negatively their attack velocity and defense velocity.

4) Regarding non-KO victories and $\mathrm{KO}$ losses, the most advantaged are Scorpio signs. Contrary to other Water signs which are used to detest all form of conflict, they often seek out challenges and problems, subliminally realizing that such challenges call forth their greatest strength and resources. That may probably have helped them not to neglect their attack, what was expectable in other Water signs.

5) Regarding all victories pulled together, all losses pulled together, and non-KO losses, the most advantaged are Virgo signs. Regarding KO victories, the most advantaged are Taurus signs. As other Earth signs, when driven back against a wall, Virgo and Taurus are capable of hitting the obstacle hard with full force. That is particularly true of Taurus, the fixed Earth, who will never seek out conflicts but who is capable of surprising power. The known soundness of Earth signs may have helped Virgo and Taurus signs to control both their attack and defense actions, performing them only when they have felt that they were going to be successful.

6) Regarding boxers career length, significant difference has not been found when comparison was called for between the means of the 12 zodiacal signs.

7) Regarding boxers life spans, the most advantaged are Libra signs and Taurus signs.

\section{Perspective}

In some poor regions of the World, there exists a lack of modern tools for identification of the candidates more advantaged than others to boxing practice. The present study has revealed pertaining of the boxer to a given zodiacal sign as a cheap tool usable for the purpose. We are already in search of other deep tools usable for the same purpose.

\section{REFERENCES}

Ackland, T. R., Bloomfield, J., \& Elliot, B. C. (2009). The assessment and modification model. In T. R. Ackland, B. C. Elliot, \& J. Bloomfield (Eds.), Applied anatomy and biomechanics in sport (pp. 3-9). Champain, IL: Human Kinetics.

Arroyo, S. (1975). Astrology, psychology and the four elements: An energy approach to astrology \& its use in the counseling arts. Sebastopol, CA: CRCS Publications.

Parker, R. E. (1979). Introductory statistics for biology ( $2^{\text {nd }}$ ed.). New York: Cambridge University Press. 